Washington University School of Medicine Digital Commons@Becker

Open Access Publications

2020

\title{
Incipient alcohol use in childhood: Early alcohol sipping and its relations with psychopathology and personality
}

\author{
Ashley L Watts \\ University of Missouri \\ Phillip K Wood \\ University of Missouri \\ Kristina M Jackson \\ Brown University \\ Krista M Lisdahl \\ University of Wisconsin - Milwaukee \\ Mary M Heitzeg \\ University of Michigan - Ann Arbor
}

See next page for additional authors

Follow this and additional works at: https://digitalcommons.wustl.edu/open_access_pubs

Please let us know how this document benefits you.

\section{Recommended Citation}

Watts, Ashley L; Wood, Phillip K; Jackson, Kristina M; Lisdahl, Krista M; Heitzeg, Mary M; Gonzalez, Raul; Tapert, Susan F; Barch, Deanna M; and Sher, Kenneth J, "Incipient alcohol use in childhood: Early alcohol sipping and its relations with psychopathology and personality." Development and Psychopathology. 1 13. (2020).

https://digitalcommons.wustl.edu/open_access_pubs/9446

This Open Access Publication is brought to you for free and open access by Digital Commons@Becker. It has been accepted for inclusion in Open Access Publications by an authorized administrator of Digital Commons@Becker. For more information, please contact vanam@wustl.edu. 


\section{Authors}

Ashley L Watts, Phillip K Wood, Kristina M Jackson, Krista M Lisdahl, Mary M Heitzeg, Raul Gonzalez, Susan F Tapert, Deanna M Barch, and Kenneth J Sher 


\title{
Regular Article
}

\section{Incipient alcohol use in childhood: Early alcohol sipping and its relations with psychopathology and personality}

\author{
Ashley L. Watts ${ }^{1}$ (D), Phillip K. Wood ${ }^{1}$, Kristina M. Jackson², Krista M. Lisdahl ${ }^{3}$, Mary M. Heitzeg ${ }^{4}$, Raul Gonzalez ${ }^{5}$, \\ Susan F. Tapert ${ }^{6}$, Deanna M. Barch ${ }^{7}$ and Kenneth J. Sher ${ }^{1}$ \\ ${ }^{1}$ Department of Psychological Sciences, University of Missouri, Columbia, MI, USA; ${ }^{2}$ Center for Alcohol and Addiction Studies, Brown University, Providence, USA; \\ ${ }^{3}$ Department of Psychology, University of Wisconsin-Milwaukee, Milwaukee, WI, USA; ${ }^{4}$ Department of Psychiatry, University of Michigan, Ann Arbor, MI, USA; \\ ${ }^{5}$ Department of Psychology, Florida International University, Miami, FL, USA; ${ }^{6}$ Department of Psychiatry, University of California San Diego, La Jolla, CA, USA and \\ ${ }^{7}$ Departments of Psychological \& Brain Sciences, Psychiatry and Radiology, Washington University, St. Louis, MO, USA
}

\begin{abstract}
Prior research has shown that sipping of alcohol begins to emerge during childhood and is potentially etiologically significant for later substance use problems. Using a large, community sample of 9 - and 10 -year-olds $(N=11,872 ; 53 \%$ female), we examined individual differences in precocious alcohol use in the form of alcohol sipping. We focused explicitly on features that are robust and well-demonstrated correlates of, and antecedents to, alcohol excess and related problems later in the lifespan, including youth- and parent-reported externalizing traits (i.e., impulsivity, behavioral inhibition and activation) and psychopathology. Seventeen percent of the sample reported sipping alcohol outside of a religiously sanctioned activity by age 9 or 10 . Several aspects of psychopathology and personality emerged as small but reliable correlates of sipping. Nonreligious sipping was related to youth-reported impulsigenic traits, aspects of behavioral activation, prodromal psychotic-like symptoms, and mood disorder diagnoses, as well as parent-reported externalizing disorder diagnoses. Religious sipping was unexpectedly associated with certain aspects of impulsivity. Together, our findings point to the potential importance of impulsivity and other transdiagnostic indicators of psychopathology (e.g., emotion dysregulation, novelty seeking) in the earliest forms of drinking behavior.
\end{abstract}

Keywords: alcohol sipping, novelty seeking, personality, precocious alcohol use, psychopathology

(Received 18 November 2019; revised 26 March 2020; accepted 30 March 2020)

Although few children initiate regular substance use in late childhood (Young et al., 2002), prior research has shown that sipping of alcohol begins to emerge during this period of development and is potentially etiologically significant for later substance use problems (e.g., Colder, Shyhalla, \& Frndak, 2018; Donovan \& Molina, 2014; Jackson, Barnett, Colby, \& Rogers, 2015). The limited literature on sipping has tended to focus on either consequences or contextual correlates of alcohol sipping (i.e., the role of parental drinking status, parental approval of drinking; Donovan \& Molina, 2008, 2011, 2014; Jackson, Ennett, Dickinson, \& Bowling, 2012), as opposed to dispositional or other psychological factors (cf., Jackson, Colby, Barnett, \& Abar, 2015; Wadolowski et al., 2015). This paucity of research persists in spite of well-established evidence that impulsigenic personality traits and externalizing tendencies are robust risk factors for adolescent and adult alcohol use (for reviews, see Sher, Littlefield, \& Lee, 2018; Tully \& Iacono, 2016). The present study aimed to address this gap in the literature by examining the

Author for Correspondence: Ashley L. Watts, Department of Psychological Sciences, 200 S. 7th Street, Columbia, MO 65211, USA. Email: ashleylwatts@gmail.com

Cite this article: Watts AL, Wood PK, Jackson KM, Lisdahl KM, Heitzeg MM, Gonzalez R, Tapert SF, Barch DM, Sher KJ (2020). Incipient alcohol use in childhood: Early alcohol sipping and its relations with psychopathology and personality. Development and Psychopathology 1-13. https://doi.org/10.1017/S0954579420000541 psychopathology and personality correlates of alcohol sipping among a large community sample of 9 - and 10-year-olds.

\section{Early alcohol initiation and its correlates}

Early alcohol initiation is concurrently and prospectively associated with a host of negative outcomes in adolescence and early adulthood (e.g., Ellickson, Tucker, Klein, \& McGuigan, 2001; Ellickson, Tucker, \& Klein, 2003; King \& Chassin, 2007; Stueve \& O'Donnell, 2005). It is especially predictive of subsequent alcohol problems. For instance, DeWit et al. (2000) reported that 14 to $16 \%$ of children who had their first drink around the age of 12 were diagnosed with alcohol abuse and dependence, respectively, 10 years later. In contrast, a mere 1 to $2 \%$ of those who drank at age 19 or older developed alcohol abuse or dependence diagnoses in this same 10-year period. In general, risk for later alcohol and psychosocial problems is more pronounced for those who initiate alcohol earlier (e.g., Grant, Stinson, \& Harford, 2001). As such, it is critical to establish risk factors that appear to contribute to excessive and potentially problematic drinking across the lifespan.

Of the established risk factors for alcohol use and misuse in adolescence, several aspects of psychopathology and personality are chief among them. Impulsivity and externalizing psychopathology, in particular, tend to be among the most reliable, robust, and well-replicated correlates of alcohol use (McGue, Iacono, 
Legrand, Malone, \& Elkins, 2001; Sher, Trull, Barthoolow, \& Vieth, 1999; Stautz \& Cooper, 2013; Tully \& Iacono, 2016). Impulsivity tends to be elevated in heavy drinkers (Rubio et al., 2008), those diagnosed with alcohol use disorder (Bjork, Hommer, Grant, \& Danube, 2004; Dom et al., 2006), and even children of parents diagnosed with substance use disorders (Haeny et al., 2019; Verdejo-García, Lawrence, \& Clark, 2008). Similarly, externalizing psychopathology assessed early in the lifespan is associated with having tried alcohol and other substances by late adolescence, as well as regular and advanced experience with these substances. Internalizing psychopathology with the exception of major depression, in contrast, tends not to be a robust predictor of alcohol use and misuse (King, Iacono, \& McGue, 2004; cf., Hussong et al., 2011). Moreover, although alcohol typologies have largely been abandoned, Type 2 (Cloninger, 1987) and Type B (Babor et al., 1992) "alcoholism" are both characterized by precocious alcohol use, alcohol excess, and antisocial behavior. Such observations highlight the intertwined nature of these constructs.

\section{Sipping as a form of precocious alcohol use}

Although most researchers tend to study precocious alcohol use among adolescents, others have extended the study of precocious alcohol use to children, in turn focusing on alcohol sipping. Alcohol sipping is relatively nonnormative in children, at least compared with adolescents (Donovan \& Molina, 2008, 2011; Jackson, Barnett et al., 2015). For instance, rates of sipping outside of a religious context range anywhere from 12 to $48 \%$ depending on the study (Donovan \& Molina, 2008; Jackson, Barnett et al., 2015). Given the relative nonnormativity of alcohol consumption at this age, it seems likely that individual differences reflecting tendencies toward psychosocial deviance differentiate those who sip alcohol in childhood and those who do not.

At least two other lines of research substantiate the study of sipping as an indicator of problematic alcohol initiation (cf., Wadolowski et al., 2015). First, sipping in childhood bears homotypic continuity with later forms of alcohol use (Donovan \& Molina, 2011; Jackson, Barnett et al., 2015). Research has found that, compared with their abstaining counterparts, 10-year-old sippers were more likely to initiate drinking by age 14 (Donovan \& Molina, 2011). Additionally, 9-year old sippers were more likely to consume a full drink, get drunk, drink heavily (three or more drinks in one occasion), and use other drugs by grade 9 (Jackson, Ennett, Dickinson, \& Bowling, 2013; Jackson, Barnett et al., 2015). Second, previously alcohol-naïve children experience the positive physiological and psychological effects of alcohol after consuming even half of an alcoholic beverage (Donovan, 2009). Together, this research suggests that late childhood is a salient developmental period in which many children have their first potentially positive experience with alcohol. Childhood is therefore a critical period to identify early forms of problematic alcohol use behavior and its potential correlates.

Among the first to study sipping among children, Donovan and Molina $(2008,2014)$ found that sipping among 8- and 10 -year-olds was associated with parental drinking, perceived parental approval of child's drinking, maternal drinking frequency, and children's attitudes towards sipping alcohol. They also found that sipping was associated with both susceptibility to peer pressure and friends' approval of sipping. In contrast, sipping was not associated with putative dispositional factors, such as religiosity, deviance proneness, and prosociality (Donovan \& Molina, 2008, 2014). With this evidence in mind, Donovan and
Molina (2014) contended that sipping among children reflects parental modeling and increased opportunities to try alcohol in the home, as opposed to psychosocial proneness to engage in problem behavior. This conclusion has been further corroborated by data from Wadolowski and colleagues (2015), who found that sipping among Australian youth around 12 years of age was unassociated with internalizing and externalizing psychopathology. Yet others find evidence to the contrary, implicating psychopathology, personality, and other developmental factors in early alcohol sipping in addition to contextual factors. In particular, limited research suggests that impulsigenic traits (i.e., lack premeditation, positive and negative urgency, sensation seeking; Gunn \& Smith, 2010; Jackson, Colby et al., 2015; Maggs, Staff, Patrick, \& WrayLake, 2019) and externalizing psychopathology (Colder et al., 2018) are all positively associated with precocious alcohol use.

\section{Present study}

In general, the potential psychopathological and dispositional correlates of alcohol sipping have received relatively little research attention. We are aware of only three such examinations to date (Colder et al., 2018; Jackson, Colby et al., 2015; Wadolwski et al., 2015). We extend the limited literature on sipping in three major ways. First, we drew upon data from the Adolescent Brain and Cognitive Development study (ABCD; Jernigan \& Brown, 2018; Lisdahl et al., 2018), a large, national, and diverse community sample of 9 - and 10-year-olds $(N=11,872 ; 53 \%$ female). A particular advantage of the ABCD sample is its size and diversity, which increases statistical power to detect small individual difference effects given the relative nonnormativity of sipping in children. Second, we differentiate sipping inside and outside of a religious context (hereafter referred to as religious and nonreligious sipping, respectively), which has not received a great deal of attention in the literature (cf., Morean, Corbin, \& Fromme, 2012). Given that the latter is more likely to occur without parental permission than the former, it is possible that these two forms of sipping bear differentiable relations with psychopathology and personality. For instance, nonreligious, but not religious, sipping might be a useful marker of traits and features of psychopathology associated with a lack of conventionality and rule breaking. Third, we focused explicitly on a wide array of constructs that are well-established correlates of alcohol use and alcohol use disorders among adolescents and adults, including externalizing and internalizing psychopathology (King, Iacono, \& McGue, 2004), impulsigenic traits (Gunn \& Smith, 2010), and parental history of alcoholism (Dawson, 2000). Alcohol involvement is intimately associated with psychopathology and personality later in development, but it is unclear when such associations might begin to emerge. The present study aims to make inroads into this broad question.

\section{Hypotheses}

All hypotheses were informed by the existing youth and adult literatures to the extent possible. At the same time, it is worth noting that we predicted reliable psychopathology and personality individual differences in sipping, which is inconsistent with conclusions drawn from some of the existing sipping literature (Donovan \& Molina, 2008, 2014; Wadolowski et al., 2015). In our view, it is possible that this prior work did not have sufficient sample sizes or variance in sipping to detect such relationships, nor was psychopathology assessed as extensively as it is in the present study.

Because sipping is nonnormative at the ages of 9 and 10, we hypothesized that features of impulsivity and externalizing- 
including unconventionality, risk-taking, and/or rule-breakingwould be associated with nonreligious sipping but not religious sipping (Colder et al., 2018; Gunn \& Smith, 2010; Jackson, Colby et al., 2015; cf., Donovan \& Molina, 2014; Wadolowski et al., 2015). Given the novelty of alcohol and drugs at this age, we also predicted that traits related to novelty seeking (i.e., fun seeking, sensation seeking) would be associated with nonreligious sipping; we expected that these associations would arise given that fun seeking tends to be one of the more reliable predictors of substance involvement in older samples (Jackson, Colby et al., 2015; Johnson, Carver, \& Joormann, 2013). We hypothesized more provisionally that internalizing (e.g., depression, anxiety) and behavioral inhibition would not be robustly associated with sipping (Hundt, Kimbrel, Mitchell, \& Nelson-Gray, 2008). This hypothesis was based on both the previous sipping literature (e.g., Colder et al., 2018; Wadolowski et al., 2015) and the broader literature in which negative emotionality is only weakly associated with alcohol use and alcohol use disorder (Sher et al., 2005; Trull \& Sher, 1994). In sum, we expected all correlates of sipping to arise only for nonreligious sipping; that is, we did not predict that psychopathology or personality would be markedly associated with religious sipping.

\section{Methods}

\section{Participants and procedure}

Participants were drawn from the full baseline sample of the ACBD study (Data Release 2.0), a sample of 11,872 9- and 10-year-olds from the US ( $M_{\text {age }}=120$ months or 10.0 years, $S D=7$ months; $53 \%$ female). The ABCD study is a collaboration between 21 sites across the US (see Garavan et al., 2018 and Jernigan \& Brown, 2018 for an overview of the methods and recruitment strategies). Fifty-eight percent of youth participants identified as White, $20 \%$ as Hispanic, $10 \%$ as Black, $2 \%$ as Asian, and $10 \%$ as Other. Twenty-seven percent of youth's parents reported being either nonreligious (atheist, agnostic) or not particularly religious, 33\% reported practicing a religion where alcohol consumption is a component of religiously sanctioned rituals (i.e., Mainline Protestant, Catholicism, Judaism), and $21 \%$ reported practicing a religion where alcohol consumption is not a component of religiously sanctioned rituals (e.g., Evangelical Protestant, Historically Black Church, Mormon, Jehovah's Witness, Muslim, Buddhist).

Thirty percent of parents reported a combined household income of $\$ 0-50,000(0-50,000), 28 \%$ of $\$ 50,001-100,000$, and $42 \%$ of $\$ 100,001$ or greater. Seven percent of parents reported a highest level of education as completing less than a high school diploma, $11 \%$ as completing high school or a General Education Diploma (GED), $29 \%$ as completing some college, $28 \%$ as completing a Bachelor's degree, and $25 \%$ as completing a graduate degree (e.g., MA, JD, PhD). Sixty-eight percent of parents were married, $13 \%$ divorced or separated, $12 \%$ never married, $6 \%$ living with partner, and $1 \%$ widowed.

\section{Measures}

\section{Sipping}

Youth self-reported on an adapted version of the iSay Sip Inventory (Jackson, Barnett et al., 2015), a 10-item measure of alcohol sipping. This assessment was only administered to participants who had heard of alcohol; it was assumed that they had not yet sipped alcohol if they have not heard of it (see Lisdahl et al., 2018, for a thorough description of the substance use battery in ABCD). Participants report whether they have ever had a sip of alcohol, and if so whether they have sipped alcohol outside of a religious context. If participants reported sipping outside of a religious context, they then reported the number of occasions in which they have sipped alcohol overall and in a nonreligious context, the age at which they had their first sip of alcohol outside of a religious context, and whether they had ever finished a full alcoholic drink. ${ }^{1}$ The number of occasions in which participants have sipped in a religious context was then computed by subtracting the number of occasions in which they report sipping in a nonreligious context from the number of occasions in which they report any sipping. In contrast with existing research (Donovan \& Molina, 2008; Jackson, Colby et al., 2015), the present study relies on the number of occasions sipped, as opposed to a dichotomous indicator reflecting whether a participant has ever sipped alcohol, to take into account frequency of drinking (see the Modeling section for more information).

\section{Youth-reported psychopathology and personality}

Youth completed several well-validated instruments assessing psychopathology and personality, each of which have been validated for use in youth samples. These included the Kiddie Schedule for Affective Disorders and Schizophrenia (KSADS-5) for the fifth edition of the Diagnostic and Statistical Manual of Mental Disorders (DSM-5; Kobak, Kratochvil, Stanger, \& Kaufman 2013; Townsend et al., 2020), the Prodromal Questionnaire-Brief Version (PQ-B; Loewy, Pearson, Vinogradov, Bearden, \& Cannon, 2011; Karcher et al., 2018), and abbreviated youth versions of the UPPS-P Impulsive Behavior scales (UPPS-P; Cyders et al., 2007; Watts, Smith, Barch, \& Sher, 2020) and Behavioral Inhibition and Activation scales (BIS/ BAS; Pagliaccio et al., 2016; see Barch et al., 2018, for a thorough description of the mental health battery in ABCD). Example items are provided for noncopyrighted instruments.

\section{KSADS-5}

The KSADS- 5 was administered to children with the help of a research assistant using a computer-based structured interview designed to assess current psychopathology in children and adolescents (Townsend et al., 2020). Youth reported on DSM-5 diagnoses for current and past mood and anxiety disorders. Because base rates for individual diagnoses were extremely low (ranged from $0.2 \%$ [child-reported current bipolar II] to $3.5 \%$ [childreported past bipolar I]), we collapsed current and past disorder diagnoses into lifetime disorder diagnoses, and further collapsed these diagnoses into dichotomous (present/absent) lifetime mood and lifetime anxiety disorder indicators.

\section{$P Q-B$}

The PQ-B comprises 21 items designed to assess symptoms associated with subclinical manifestations of psychosis (e.g., "Did you ever feel very certain that you have very special abilities or magical talents that other people do not have?"; $\alpha=.86$; mean corrected item-total correlation $=.45$ ). Items are answered in a dichotomous response format and are summed to reflect total number of symptoms endorsed (True/False).

\footnotetext{
${ }^{1}$ Participants also completed other follow-up questions that were not the focus of the present study, including: what type of alcohol was tried the first time they sipped (e.g., beer, wine, liquor); to whom the drink belonged (e.g., parent, sibling, friend); whether the sip was offered as opposed to taken without permission; and whether the participant remembered trying the sip, or if he/she was told about it later.
} 


\section{UPPS-P}

The abbreviated youth version of the UPPS-P Impulsive Behavior scales (Watts et al., 2020) comprises 20 items assessing five broad impulsivity dimensions: Lack of Perseverance, the inability to sustain attention or motivation to complete a task (e.g., "I finish what I start"); Lack of Premeditation, the tendency to not plan ahead and behave without thinking (e.g., "I am very careful"); Negative Urgency, the tendency to act hastily when in an extreme negative mood state (e.g., "When I am upset, I often act without thinking"); Positive Urgency, the tendency to act hastily when in an extreme positive mood state (e.g., "I tend to lose control when I am in a great mood"); and Sensation Seeking, the inclination towards seeking out novel, thrilling experiences (e.g., "I enjoy taking risks"; Cronbach (coefficient) alpha ranged from .50 [Sensation Seeking] to .78 [Positive Urgency]). Items were rated on a 0 (agree strongly) to 4 (disagree strongly) scale. The relatively low internal reliability for the Sensation Seeking scale was driven by a single item that did not load highly onto the factor (Watts et al., 2020). Median corrected item-total correlation (MCITCs) were as follows: .53 (Lack of Premeditation), .48 (Lack of Perseverance), .41 (Negative Urgency), .30 (Sensation Seeking), and .58 (Positive Urgency).

\section{BIS/BAS}

The BIS/BAS comprises 20 items assessing two broad motivational systems, the behavioral inhibition (BIS) and behavioral activation (BAS) systems (Gray, 1982). BIS is sensitive to signals of punishment and nonreward, novel stimuli, and innate fear stimuli, resulting in avoidance and negative emotionality, whereas BAS is sensitive to positive reinforcement and the absence of punishment, resulting in approach and positive emotionality. The BIS/BAS includes one subscale for BIS (e.g., "I worry about making mistakes") and three for BAS: Drive (e.g., "I go out of my way to get things I want"), Fun Seeking (e.g., "I crave excitement and new sensations"), and Reward Responsiveness (e.g., "When I'm doing well at something I love to keep at it"; $\alpha$ s ranged from .63 [Inhibition] to .77 [Reward Responsiveness]). Items were rated on a 0 (not true) to 3 (very true) scale. MCITCs ranged from .33 [Inhibition] to .59 [Drive]). Items were rated on a 0 (not true) to 3 (very true) scale. ${ }^{2}$

\section{Parent-reported youth psychopathology}

Parents rated their child on several additional well-validated instruments assessing psychopathology, including the Child Behavior Checklist (CBCL; Achenbach \& Rescorla, 2001), an abbreviated scale assessing dimensional mania symptoms (Youngstrom, Frazier, Demeter, Calabrese, \& Findling, 2008) adapted from the Parent General Behavior Inventory (P-GBI; Youngstrom, Findling, Danielson, \& Calabrese, 2001), and the KSADS-5. In addition, parents reported on parental history of alcohol problems on the Family History Assessment Module Screener (FHAM-S; Rice et al., 1995).

\footnotetext{
${ }^{2}$ Although conceptually overlapping with the UPPS-P scales, we elected to examine both the BIS/BAS and UPPS-S scales. A recent examination (Watts et al., 2020) in the $\mathrm{ABCD}$ baseline sample found that these sets of scales are overlapping but not isomorphic. In general, there is only large convergence between one pairing of scales, BAS Fun Seeking and UPPS-P Sensation Seeking $(r=.57)$, although others display moderate convergence, including BAS Fun Seeking with UPPS-P Negative Urgency $(r=.40)$ and Positive Urgency $(r=.36)$; and BAS Drive and UPPS-P Sensation Seeking $(r=.38)$. Especially pronounced associations between BAS Fun Seeking and UPPS-P Sensation Seeking are expected given that, at least in part, they ostensibly probe overlapping latent constructs, including novelty seeking (e.g., Segarra et al., 2014).
}

CBCL

The CBCL includes 118 items that coalesce into two broad scores for Externalizing (includes subscales for Rule-breaking Behavior $\&$ Aggressive Behavior; $\alpha=.92, \mathrm{MCITC}=.40$ ) and Internalizing (includes subscales for Social Withdrawal, Somatic Complaints, Anxiety/Depression; $\alpha=.89, \mathrm{MCITC}=.38$ ) that comprise two and three subscales, respectively. It also provides subscale scores for Thought Problems, Attention Problems, and Social Problems. Items are rated on a 0 (not true) to 2 (very true or often true) scale. We focus our exposition of the results on the Externalizing and Internalizing composites, as well as the Thought Problems subscale. Results for all CBCL subscales are reported in Supplementary Table 9; there were no significant differences in effect sizes across subscales within Externalizing and Internalizing composites.

\section{Dimensional mania}

The dimensional mania scale comprises 10 items taken from the P-GBI, a longer inventory that comprises 73 items pertaining to mood (e.g., "Has your child's mood or energy shifted rapidly back and forth from happy to sad or high to low?"); items were summed into a single composite $(\alpha=.85$; MCITC $=.58)$. Items are rated on a 0 (never or hardly ever) to 3 (very often or almost constantly) scale.

\section{KSADS-5}

Parents reported on their child's current and past mood, affect, externalizing (i.e., conduct disorder, oppositional defiant disorder, and attention-deficit/hyperactivity disorder), and eating disorders (i.e., anorexia nervosa, bulimia, binge eating disorder), as well as associated psychotic symptoms (i.e., delusions, hallucinations). Again due to low base rates, we collapsed current and past disorder diagnoses into lifetime disorder diagnoses, and then collapsed these diagnoses into lifetime mood, anxiety, externalizing, and eating disorder categories (present/absent), as well as an associated psychotic symptoms category (present/absent).

\section{Parental history of alcohol problems}

We extracted a dichotomous indicator of parental history of alcohol problems (no history/at least one parent with history) from the FHAM-S, in which parents reported on the presence/absence of problems and symptoms associated with alcohol use disorder in both of the child's biological parents.

\section{Data analysis}

\section{Demographic covariates}

All models included the following demographic covariates: age, gender, ethnicity, religion, combined household income, parental education, and parental marital status. We included age, gender, ethnicity, combined household income, parental education, and parental marital status, as covariates in light of demographic differences in sipping reported elsewhere (Lisdahl et al., in preparation). We describe our rationale for including religion as a covariate later (see Results). In these models, age was continuous, and household income contained 10 ordered categories, so we treated it essentially continuous. There were four dummy coded variables for race/ethnicity, one each for Black, Hispanic, Asian, and Other, where White was the reference group. We categorized youth into one of three categories based on their reported religion. The first was a "nonreligious" group (i.e., Atheist, Agnostic, no particular religion), the second was a group of religions/ Christian denominations where at least some religiously 
sanctioned alcohol consumption was reported, and the third was a group of religions/Christian denominations where religiously sanctioned alcohol consumption was not reported; here, "nonreligious" was the reference group. ${ }^{3}$ There were four dummy coded variables for parental education, one each for (a) less than a high school education, (b) finished high school or GED, (c) finished some college, or (d) obtained Bachelor's degree, where obtained a graduate degree was the reference group. There were three dummy coded variables for parental marital status, one each for (a) separated/ divorced, (b) never married, and (c) other (i.e., widowed, living with partner; these categories were combined due to low rates of endorsement), where married was the reference group.

\section{Sipping indicators}

We winsorized all continuous number of times sipped indicators to eliminate extreme values at the 95th percentile and reduce the potential for influential but spurious outliers. This resulted in sipping indicators that could be described by four categories: $0,1,2$, and 3 or more sipping occasions. ${ }^{4}$ The number of sipping occasions indicators (overall, religious, nonreligious) were treated as an ordered polytomous variable, whereas the age of first sip of alcohol was treated as continuous. We conducted ordinal logistic regressions for the former and linear regressions for the latter.

\section{Modeling}

We conducted all analyses using Mplus version 8.3 (Muthén \& Muthén, 1998-2017). Analyses accounted for the nesting of participants within data collection site (stratum) and family (cluster) to account for nonindependence among participants collected at each site and among siblings within the same family.

Ordinal logistic regressions using the MLR estimator (maximum likelihood with robust standard errors) specified the number of sipping occasions indicator as categorical, which provides proportional odds ratios in addition to unstandardized regression coefficients. Brant Wald tests of proportional odds were nonsignificant for all psychopathology and personality indicators, supporting the assumption of proportional odds (or parallel regression) across levels of sipping. In other words, when nonsignificant, these tests indicate that odds ratios to describe the relationship between the lowest and all higher levels of sipping, for instance, are the same as those that describe the relationship

\footnotetext{
${ }^{3}$ Religions were classified as falling into one of the latter two categories on the basis of one-sample $t$ tests in which frequencies of religious sipping occasions within each category of religion were compared against zero. Frequencies of religious sipping were significantly different from zero for the following religions/Christian denominations, indicating that alcohol sipping is at least somewhat religiously sanctioned during ceremonial rituals: Mainline Protestant (e.g., Lutheran, Presbyterian), Catholicism, Judaism, and a catchall category termed Other Christian which did not include Mainline or Evangelical (e.g., Baptist) Christian denominations; as such, individuals who practice those religions were sorted into the first religious category. Frequency of religious sipping was not significantly different from 0 for all other religions/Christian denominations (e.g., Mormonism, Buddhist, Hindu, Historically Black Churches, Jehovah's Witness), and as such they were included in the third category.

${ }^{4}$ We used 4-category indicators given sparseness in the uppermost levels of the sipping outcomes with 5,6 , and so on categories. For comprehensiveness, we examined alternate versions of sipping outcomes with $5(0,1,2,3$, and $4+$ sipping occasions $)$ and $6(0,1,2,3$, 4 , and $5+$ sipping occasions) categories. We found statistically identical results for the 5 and 6-category sipping indicators (the maximum difference in odds ratios across the models was .012), but we had difficulty obtaining Brant Wald tests of proportional odds for the 5-category religious sipping indicator and 6-category sipping indicators This was likely due to the sparseness of the sipping indicators and external criteria at the upper end of the distributions. For the 5-category nonreligious sipping indicator, Brant Wald tests were nonsignificant, indicating proportional odds across the 5 levels of nonreligious sipping. These results are available from the first author upon request.
}

between the next lowest level of sipping and all higher categories, and so on. As such, proportional odds facilitate the comparison of our odds ratios for number of sipping occasions with those in the existing literature, which tend to use dichotomous (no/yes) indicators of sipping. All continuous independent variables were standardized to facilitate interpretation of the odds ratios (i.e., to maintain a common metric to aid in comparisons).

\section{Results}

\section{Sipping characteristics}

Twenty-three percent of youth reported having sipped alcohol under any condition, and $17 \%$ reported nonreligious sipping (76\% of those who reported sipping at all). The average age at which youth who reported first sipping alcohol was 7.31 years $(S D=1.90)$. Sipping occasions, on average, were limited in number. Sippers reported an average of 1.11 sipping occasions overall $(S D=11.72$, range 0 to 777 for religious sipping, range 0 to 198 for nonreligious sipping), and an average of .48 nonreligious sipping occasions $(S D=3.35)$. Of sippers who reported sipping in a nonreligious context, $55 \%$ reported sipping once, $22 \%$ twice, $10 \%$ three times, $3 \%$ four times, $4 \%$ five times, and $7 \%$ reported sipping six or more times (see Supplementary Tables 1 and 2 for descriptive statistics and frequencies of sipping).

The numbers of religious and nonreligious sipping occasions were weakly correlated $(r=.06)$. The number of religious sipping occasions was not associated with the age of first nonreligious sip $(r=.01)$. The number of nonreligious sipping occasions was slightly negatively associated with the age of first nonreligious $\operatorname{sip}(r=-.08)$. Of the youth who reported nonreligious sipping, only $1.6 \%(n=33)$ reported consuming an entire alcoholic beverage at least once $(.23 \%$ of the overall sample; see Table 1 for summary statistics). The small number $(n=33)$ of children reporting having consumed a full drink precluded stable and well-powered regression analyses, so we elected not to move forward with this variable in external validity analyses (see also Colder et al., 2018).

\section{Psychopathology and personality correlates of sipping ${ }^{5}$}

As has been reported elsewhere, there were significant differences in religious and nonreligious sipping across several demographic

${ }^{5} \mathrm{We}$ also conducted linear and generalized linear mixed models to examine mean-level differences in psychopathology and personality across "types" of sippers. For all mixed models, we classified youth into one of four categories on the basis of their reported alcohol sipping, those who reported: (a) never having sipped alcohol, (b) sipping in a religious context (for a religiously sanctioned purpose) only, (c) sipping in both a religious and nonreligious context, and (d) sipping in a nonreligious context only. These analyses were conducted using R version 3.5.1 (R Core Team, 2018), and the gamm4 (Wood \& Scheipl, 2017) and emmeans (Lenth, Singmann, Love, Buerkner, \& Herve, 2018) packages. These results mirrored the findings we report in the main text. Omnibus tests from linear mixed models were significant $(p<.001)$ for a number of continuous psychopathology and personality indicators, including: UPPS-P Lack of Perseverance, Lack of Premeditation, Negative Urgency, Positive Urgency, Sensation Seeking, BAS Fun Seeking, and PQ-B prodromal symptoms (Fs ranged from 5.89 to 38.00). These effects were explained by significant linear associations between the aforementioned psychopathology and personality indicators and sipping status ( $t$ s ranged from 3.48 to 7.31 ). In general, there were monotonic associations with sipping status such that levels of impulsigenic and prodromal features increased as a function of sipping status. Tukey-adjusted pairwise comparisons indicated, however, that much of these linear associations arose due to by pairwise differences between the "never sipped" and the "only nonreligious sipped" groups; this was true for each of the UPPS-P factors, BAS Fun Seeking, and PQ-B prodromal symptoms. There were, moreover, significant pairwise comparisons indicating differences between the "never sipped" and "only religious sipped" groups for UPPS-P Lack of Premeditation and Sensation Seeking. All results are available in Table S6. 


\begin{tabular}{|c|c|c|c|c|c|c|c|c|c|c|c|c|c|c|}
\hline & \multicolumn{12}{|c|}{ Number of alcohol sipping occasions } & \multirow{2}{*}{\multicolumn{2}{|c|}{$\begin{array}{c}\begin{array}{c}\text { Age at first } \\
\text { nonreligious sip }\end{array} \\
(n=2017 ; \\
M=7.31, S D=1.90)\end{array}$}} \\
\hline & \multicolumn{4}{|c|}{$\begin{array}{c}\text { Overall } \\
\left(n_{\text {sipped }}=2666 ; M=.40, S D=.84\right)\end{array}$} & \multicolumn{4}{|c|}{$\begin{array}{c}\text { Religious } \\
\left(n_{\text {sipped }}=832 ; M=.12, S D=.51\right)\end{array}$} & \multicolumn{4}{|c|}{$\begin{array}{c}\text { Nonreligious } \\
\left(n_{\text {sipped }}=2033 ; M=.29, S D=.72\right)\end{array}$} & & \\
\hline & B & $99 \% \mathrm{Cl}$ & $O R$ & $99 \% \mathrm{Cl}$ & B & $99 \% \mathrm{Cl}$ & $O R$ & $99 \% \mathrm{Cl}$ & B & $99 \% \mathrm{Cl}$ & $O R$ & $99 \% \mathrm{Cl}$ & $\beta$ & $99 \% \mathrm{Cl}$ \\
\hline \multicolumn{15}{|l|}{ Externalizing psychopathology ${ }^{p}$} \\
\hline CBCL Externalizing & .12 & $(.06, .19)$ & 1.13 & $(1.06,1.20)$ & .11 & $(.00, .21)$ & 1.11 & $(1.00,1.23)$ & .10 & $(.03, .17)$ & 1.11 & $(1.03,1.19)$ & .01 & $(-.05, .07)$ \\
\hline KSADS-5 Lifetime externalizing disorder & .29 & $(.15, .43)$ & 1.34 & $(1.16,1.53)$ & $.30^{\circ}$ & $(.07, .52)$ & 1.34 & $(1.08,1.68)$ & $.25^{\circ}$ & $(.10, .40)$ & 1.29 & $(1.11,1.50)$ & -.04 & $(-.10, .03)$ \\
\hline \multicolumn{15}{|l|}{ Internalizing psychopathology ${ }^{y, p}$} \\
\hline CBCL Internalizing ${ }^{p}$ & .04 & $(-.02, .11)$ & 1.04 & $(.98,1.11)$ & $-.02^{\circ}$ & $(-.12, .08)$ & .98 & $(.89,1.09)$ & $.07^{\circ}$ & $(.00, .13)$ & 1.07 & $(1.00,1.14)$ & -.05 & $(-.11, .01)$ \\
\hline KSADS-5 Lifetime mood disorder ${ }^{y}$ & .42 & $(.18, .66)$ & 1.52 & $(1.19,1.93)$ & $.07^{\circ}$ & $(-.36, .49)$ & 1.07 & $(.70,1.63)$ & $.48^{\circ}$ & $(.23, .74)$ & 1.62 & $(1.25,2.09)$ & -.04 & $(-.10, .02)$ \\
\hline KSADS-5 Lifetime mood disorder ${ }^{p}$ & .26 & $(-.01, .53)$ & 1.30 & $(.99,1.70)$ & $.18^{\circ}$ & $(-.28, .64)$ & 1.20 & $(.76,1.90)$ & $.25^{\circ}$ & $(-.04, .55)$ & 1.29 & $(.96,1.73)$ & -.03 & $(-.09, .03)$ \\
\hline KSADS-5 Lifetime anxiety disorder ${ }^{y}$ & .09 & $(-.40, .57)$ & 1.09 & $(.67,1.76)$ & $-.73^{\circ}$ & $(-1.92, .45)$ & .48 & $(.15,1.57)$ & $.26^{\circ}$ & $(-.23, .76)$ & 1.30 & $(.79,2.14)$ & -.03 & $(-.09, .03)$ \\
\hline KSADS-5 Lifetime anxiety disorder ${ }^{p}$ & -.03 & $(-.25, .20)$ & .97 & $(.78,1.22)$ & $-.20^{\circ}$ & $(-.60, .20)$ & .82 & $(.55,1.23)$ & $.07^{\circ}$ & $(-.17, .31)$ & 1.07 & $(.85,1.36)$ & -.04 & $(-.09, .02)$ \\
\hline KSADS-5 Lifetime eating disorder ${ }^{p}$ & .20 & $(-.44, .85)$ & 1.23 & $(.64,2.33)$ & $-.98^{\circ}$ & $(-2.88, .93)$ & .38 & $(.06,2.53)$ & $.35^{\circ}$ & $(-.31,1.01)$ & 1.42 & $(.74,2.76)$ & .01 & $(-.05, .06)$ \\
\hline \multicolumn{15}{|l|}{ Thought disorder psychopathology $y, p$} \\
\hline CBCL Thought Problems $^{p}$ & .05 & $(-.01, .11)$ & 1.05 & $(.99,1.12)$ & $.01^{\circ}$ & $(-.09, .12)$ & 1.01 & $(.91,1.12)$ & $.06^{\circ}$ & $(.00, .13)$ & 1.06 & $(1.00,1.14)$ & -.04 & $(-.10, .02)$ \\
\hline PQ-B prodromal symptoms ${ }^{y}$ & .24 & $(.18, .29)$ & 1.27 & $(1.19,1.34)$ & $.11^{\circ}$ & $(.02, .21)$ & 1.12 & $(1.02,1.23)$ & $.25^{\circ}$ & $(.19, .31)$ & 1.28 & $(1.21,1.36)$ & -.04 & $(-.10, .03)$ \\
\hline KSADS-5 Lifetime psychotic symptoms ${ }^{p}$ & .21 & $(-.41, .82)$ & 1.23 & $(.67,2.27)$ & $-.43^{\circ}$ & $(-1.77, .92)$ & .65 & $(.17,2.52)$ & $.32^{\circ}$ & $(-.32, .95)$ & 1.37 & $(.73,2.59)$ & .01 & $(-.05, .06)$ \\
\hline KGBI dimensional mania symptoms ${ }^{p}$ & .06 & $(-.01, .12)$ & 1.06 & $(1.00,1.13)$ & $.01^{\circ}$ & $(-.10, .12)$ & 1.01 & $(.90,1.13)$ & $.06^{\circ}$ & $(.00, .13)$ & 1.07 & $(1.00,1.14)$ & .00 & $(-.06, .06)$ \\
\hline Parental history of alcoholism ${ }^{\mathrm{P}}$ & .07 & $(-.12, .26)$ & 1.07 & $(.88,1.30)$ & $-.02^{\circ}$ & $(-.35, .32)$ & .98 & $(.71,1.37)$ & $.05^{\circ}$ & $(-.16, .26)$ & 1.05 & $(.85,1.30)$ & -.05 & $(-.12, .01)$ \\
\hline \multicolumn{15}{|l|}{ UPPS-P ${ }^{y}$} \\
\hline Lack of perseverance & .15 & $(.09, .21)$ & 1.16 & $(1.09,1.23)$ & $.10^{\circ}$ & $(.00, .20)$ & 1.10 & $(1.00,1.22)$ & $.15^{\circ}$ & $(.09, .22)$ & 1.16 & $(1.09,1.24)$ & -.08 & $(-.14,-.02)$ \\
\hline Lack of premeditation & .21 & $(.15, .27)$ & 1.23 & $(1.16,1.30)$ & .19 & $(.09, .28)$ & 1.20 & $(1.10,1.32)$ & .18 & $(.12, .25)$ & 1.20 & $(1.12,1.28)$ & -.05 & $(-.11, .01)$ \\
\hline Negative urgency & .18 & $(.12, .24)$ & 1.20 & $(1.13,1.27)$ & $.10^{\circ}$ & $(.01, .20)$ & 1.11 & $(1.01,1.22)$ & $.20^{\circ}$ & $(.13, .27)$ & 1.22 & $(1.14,1.30)$ & .03 & $(-.03, .08)$ \\
\hline Positive urgency & .15 & $(.09, .21)$ & 1.16 & $(1.09,1.23)$ & .14 & $(.04, .25)$ & 1.15 & $(1.04,1.28)$ & .13 & $(.07, .20)$ & 1.14 & $(1.07,1.22)$ & .02 & $(-.04, .07)$ \\
\hline Sensation seeking & .22 & $(.16, .28)$ & 1.25 & $(1.17,1.33)$ & .19 & $(.09, .30)$ & 1.21 & $(1.10,1.34)$ & .20 & $(.13, .27)$ & 1.22 & $(1.14,1.30)$ & .02 & $(-.04, .08)$ \\
\hline \multicolumn{15}{|l|}{ BIS/BAS $^{y}$} \\
\hline BIS Inhibition & .08 & $(.02, .14)$ & 1.08 & $(1.02,1.15)$ & .06 & $(-.04, .16)$ & 1.06 & $(.96,1.17)$ & .09 & $(.02, .15)$ & 1.09 & $(1.02,1.17)$ & -.01 & $(-.07, .05)$ \\
\hline BAS Reward Responsiveness & .05 & $(-.01, .11)$ & 1.05 & $(.99,1.12)$ & .07 & $(-.03, .17)$ & 1.07 & $(.97,1.19)$ & .04 & $(-.03, .10)$ & 1.04 & $(.97,1.11)$ & -.01 & $(-.07, .05)$ \\
\hline BAS Drive & .06 & $(-.01, .12)$ & 1.06 & $(.99,1.12)$ & .04 & $(-.06, .14)$ & 1.04 & $(.94,1.15)$ & .05 & $(-.02, .11)$ & 1.05 & $(.98,1.12)$ & -.01 & $(-.07, .05)$ \\
\hline BAS Fun Seeking & .15 & $(.09, .21)$ & 1.17 & $(1.10,1.24)$ & $.05^{\circ}$ & $(-.05, .15)$ & 1.05 & $(.95,1.16)$ & $.18^{\circ}$ & $(.11, .24)$ & 1.19 & $(1.12,1.27)$ & -.01 & $(-.07, .05)$ \\
\hline
\end{tabular}

Note. Regression weights and Odds Ratios are bolded where their false discovery rate adjusted $p$ values were $<.001$.

$\mathrm{y}=$ youth-reported $^{\mathrm{p}}=$ parent-reported.

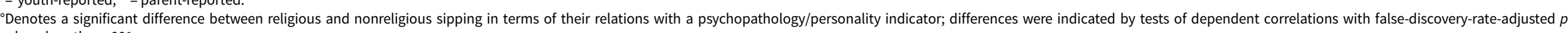

values less than .001.
All number of alcohol sipping occasions indicators included four levels. All models include age, sex, ethnicity, religion, household income, parental education, and parental marital status.

Brant Wald tests of proportional odds for each psychopathology and personality indicator were not significant $(p>.05)$, indicating proportional odds across each level of sipping. 
indicators, including age, gender, ethnicity, combined household income, parental education, and parental marital status (Lisdahl et al., in preparation; see also Supplementary Table 3). There were also differences in sipping as a function of religion. Relative to those who are not religious, youth who practice a religion where alcohol consumption is not religiously sanctioned reported lower frequencies of sipping in both religious (OR $=.26$; see Supplementary Table 3 for $99 \%$ confidence intervals) and nonreligious contexts $(O R=.34)$. Again relative to those who are not religious, youth who practice a religion where alcohol consumption is sanctioned in specific rituals reported higher frequencies of sipping in nonreligious contexts $(O R=1.59)$ but not religious contexts $(O R=.82)$.

As we noted earlier, given these demographic differences, all models included the following covariates: age, gender, ethnicity, religion, combined household income, parental education, and parental marital status. ${ }^{6}$ In addition to effect size and $99 \%$ confidence intervals, we focus our exposition of all following results on $p$ values adjusted for false discovery rate to correct for multiple comparisons (given the 88 associations between sipping and psychopathology/personality presented); $p$ values were adjusted using the fda.usc package in R (Febrero-Bande \& de la Fuente, 2012). Further, we adopted a significance threshold of $p<.001$ for all false-discovery-rate-adjusted $p$ values given increased power to detect small effects with our sample size.

\section{Nonreligious sipping}

A number of psychopathology and personality indicators were associated with a higher frequency of nonreligious sipping (see Table 1 for all associations and their 99\% confidence intervals; see also Figures 1 and 2), including: parent-reported KSADS-5 lifetime externalizing disorder diagnoses $(O R=1.29)$; youth-reported KSADS-5 lifetime mood disorder diagnoses $(O R=1.62)$; PQ-B prodromal symptom counts $(O R=1.28)$; UPPS-P Lack of Perseverance $(O R=1.16)$, Lack of Premeditation $(O R=1.20)$, Negative Urgency $(O R=1.22)$, Positive Urgency $(O R=1.14)$, and Sensation Seeking $(O R=1.22)$; and BAS Fun Seeking $(O R=$ 1.19). In subsidiary post hoc analyses, we found that the relations between child-reported KSADS-5 lifetime mood disorder diagnoses and nonreligious sipping were significant for lifetime major depressive disorder $(O R=1.51)$ and bipolar II disorder $(O R=2.25)$ diagnoses, and not significant for bipolar I disorder diagnoses $(O R=1.38)$. There was no evidence that internalizing psychopathology or family history of alcohol problems were associated with increased frequency of nonreligious sipping (ORs ranged from .38 to 1.42 ). When entered into a model simultaneously, all psychopathology and personality indicators explained $2.3 \%$ of the variance in frequency of nonreligious sipping; demographic covariates explained an additional $2.6 \%$ of the variance when included in the model (for a combined explanation of $4.9 \%$ of the variance in nonreligious sipping).

\section{Religious sipping}

Of the potential psychopathology and personality correlates of religious sipping, only UPPS-P Lack of Premeditation $(O R=$ $1.20)$ and Sensation Seeking $(O R=1.21)$ were associated with a higher frequency of religious sipping. No other indicators emerged as correlates of religious sipping. When entered into a model simultaneously, all psychopathology and personality

\footnotetext{
${ }^{6}$ Analyses without demographic covariates, those with age and gender only, and those with age, gender, ethnicity, and religion only, are reported in Supplementary Tables 4 and 5 .
}

indicators explained $1.0 \%$ of the variance in frequency of religious sipping; demographic covariates explained an additional $1.9 \%$ of the variance when included in the model (for a combined explanation of $2.9 \%$ of the variance in religious sipping).

\section{Differences between nonreligious and religious sipping}

To examine differences in the correlates of nonreligious and religious sipping, we conducted tests of dependent correlations (Steiger, 1980), which compared nonreligious and religious sipping in terms of their relations with each psychopathology and personality indicator while accounting for their covariation $(r$ $=.06$ ). Significant differences between nonreligious and religious sipping were indicated by a false discovery rate adjusted $p$ value $<.001$ (for the 22 tests conducted, one for each psychopathology and personality indicator). Table 1 denotes where there were significant differences across sipping types (see also Figures 1 and 2) and Supplementary Table 7 provides all Steiger's Z values.

Compared with frequency of religious sipping, frequency of nonreligious sipping was more strongly associated with youth-reported KSADS-5 lifetime mood disorder diagnoses, PQ-B prodromal symptoms, UPPS-P Lack of Perseverance and Negative Urgency, and BAS Fun Seeking (Steiger's Zs ranged from -4.02 to -35.67 ). Each of these indicators were not significantly associated with religious sipping. In contrast, there were no significant differences between religious and nonreligious sipping for UPPS-P Lack of Premeditation, Positive Urgency, and Sensation Seeking (Steiger's Zs ranged from -.82 to .82).

\section{Age of first nonreligious sip of alcohol}

Among those who reported nonreligious sipping $(N=2017)$, none of the psychopathology and personality indicators were significantly associated (per 99\% confidence intervals) with the age of first nonreligious sip of alcohol. Together, all psychopathology and personality indicators explained $2.8 \%$ of the variance in the age of first nonreligious sip of alcohol, with a combined explanation of $7.4 \%$ of the variance when demographic covariates were included in the model.

\section{Discussion}

There is considerable evidence that precocious alcohol use, most typically studied among adolescents, is etiologically significant for later alcohol problems. The present study extended the study of precocious alcohol use to 9- and 10-year-old children from a national, diverse community sample, focusing on alcohol sipping and its concurrent psychopathology and personality correlates. Nearly a quarter of the sample (23\%) reported sipping alcohol in some context, and $17 \%$ reported sipping outside of a religious context. These estimates generally accord with those reported in the limited literature for 9- and 10-year-olds (Colder et al., 2018; Donovan \& Molina, 2008, 2011; Jackson, Barnett et al., 2015).

\section{Key findings and implications}

To examine individual differences in sipping, we included a thorough cross-method (i.e., youth- and parent-reported) assessment of psychopathology and personality. We focused explicitly on features of psychopathology and personality (i.e., impulsivity, behavioral inhibition and activation) that are robust and well-demonstrated correlates of, and antecedents to, alcohol excess and related problems in adolescence and adulthood. 


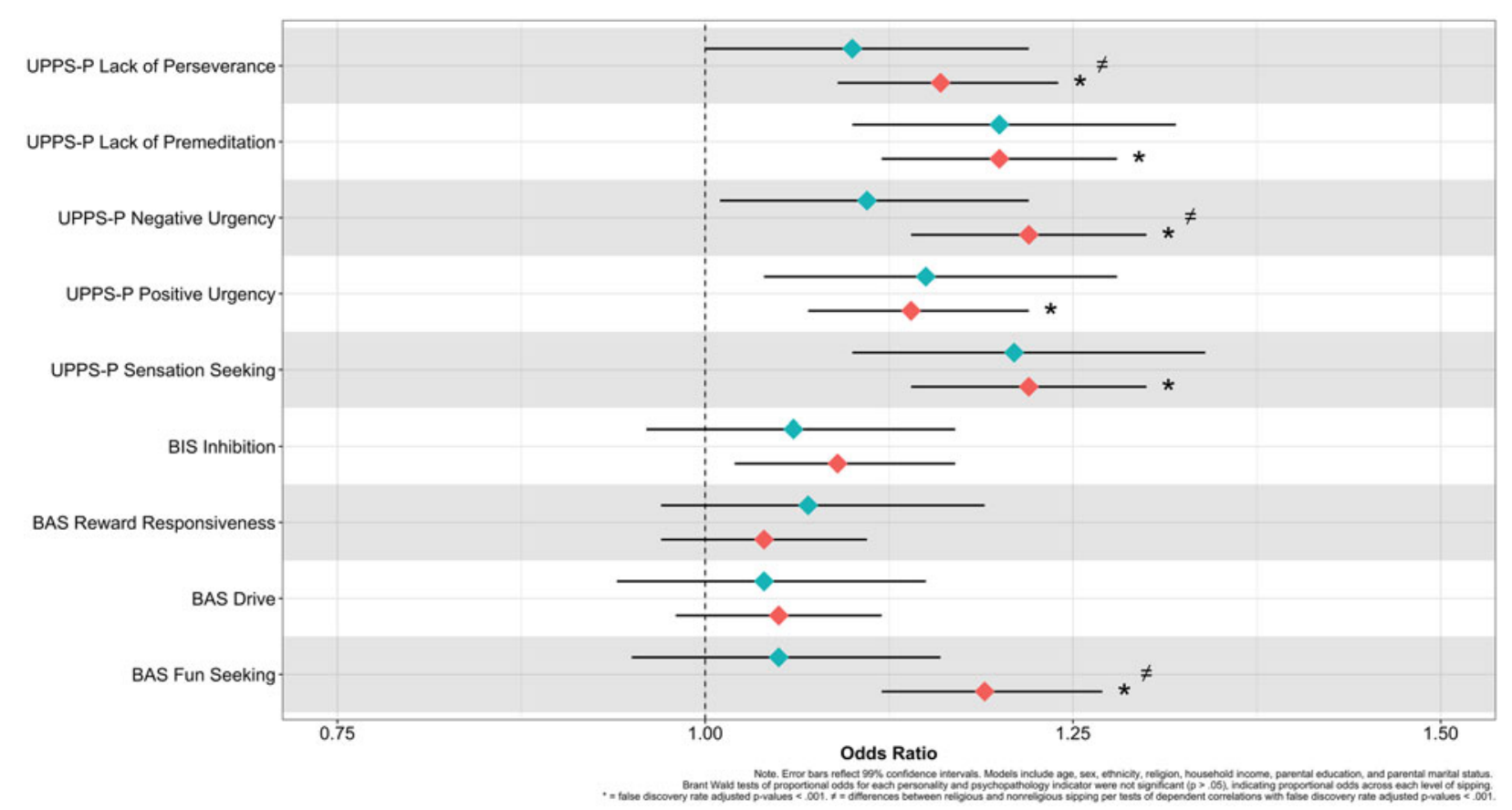

Figure 1. Odds of sipping as a function of youth-reported personality.

Several aspects of psychopathology and personality emerged as correlates of sipping. We hypothesized that such correlates would be more associated with nonreligious as opposed to religious sipping given that we view nonreligious alcohol consumption at this age as an index of psychosocial deviance

This hypothesis was generally corroborated. Youth-reported mood disorder, prodromal schizophrenia symptoms, lack of perseverance, negative urgency, and fun seeking were all positively associated with an increased frequency of nonreligious sipping, and essentially unassociated with religious sipping. Although reliable, these effects were small, perhaps even trivial. In terms of absolute risk, with a base rate of 170 in 1,000 for nonreligious sipping, a one-unit increase in mood disorder, prodromal schizophrenia, impulsivity, novelty seeking translates to anywhere from 20 to 80 additional children in 1,000 for whom starting or increasing sipping is associated with these features of psychopathology and personality (see Supplementary Table 8 for all absolute risks). Impulsivity indicators fell toward the smaller side of this range, externalizing disorders and prodromal schizophrenia symptoms fell toward the middle of this range, and mood disorder diagnoses fell on the larger side of this range. Although small, these findings suggest that tendencies towards lack of perseverance, mood dysregulation, and novelty seeking are uniquely associated with nonreligious sipping. In what follows, we offer several competing interpretations of our findings.

That impulsigenic traits across the board were associated with nonreligious sipping among children as young as 9-years-old is broadly consistent with the adolescent and adult literatures, which find that impulsivity and novelty seeking tend to be associated with precocious alcohol use and later alcohol-related excess and problems (e.g., Colder et al., 2018; Gunn \& Smith, 2010; Jackson, Colby et al., 2015). Gunn and Smith (2010) reported, for instance, that each of the UPPS-P scales were associated with early drinking when defined as consuming more than just a sip of alcohol.

That child-reported lifetime mood disorder diagnoses and prodromal symptoms were associated with sipping is especially novel. We venture that there are a number of plausible interpretations of these findings, including that they are driven by emotion (or mood) dysregulation, negative emotionality, or novelty seeking, each of which are implicated in pediatric bipolar disorder and prodromal psychosis (e.g., Marwaha, Broome, Bebbington, Kuipers, \& Freeman, 2013). We view the emotion dysregulation hypothesis as possible given that poor self-regulation is associated with sipping early in development (Jackson et al., 2013), and that alcohol consumption functions as a coping motivation among those with emotion regulation difficulties (e.g., Dvorak et al., 2014). We view the negative emotionality hypothesis as less likely given that we would expect to see significant associations between other indices probing negative emotionality, such as lifetime anxiety disorders, internalizing proneness, and behavioral inhibition, and there were none (see also Wadolowski et al., 2015). Should either our emotion dysregulation or negative emotionality hypotheses bear out in future work, it might suggest that there are two distinct pathways to alcohol use, through impulsigenic traits and either emotion dysregulation or negative emotionality.

One other, more parsimonious possibility is that novelty seeking mediates nonreligious sipping's associations with BAS Fun Seeking, mood disorder diagnosis, and prodromal schizophrenia symptoms. Some have proposed that psychosis and pediatric bipolar disorder arise from aberrant assignment of novelty and salience to objects by way of hyperdopaminergic abnormality (e.g., Kapur et al., 2003). It is possible that aberrant assignment of novelty and salience to alcohol and other substances occurs among children with elevated psychotic-like experiences. It is important to note, however, that parent-reported mania 


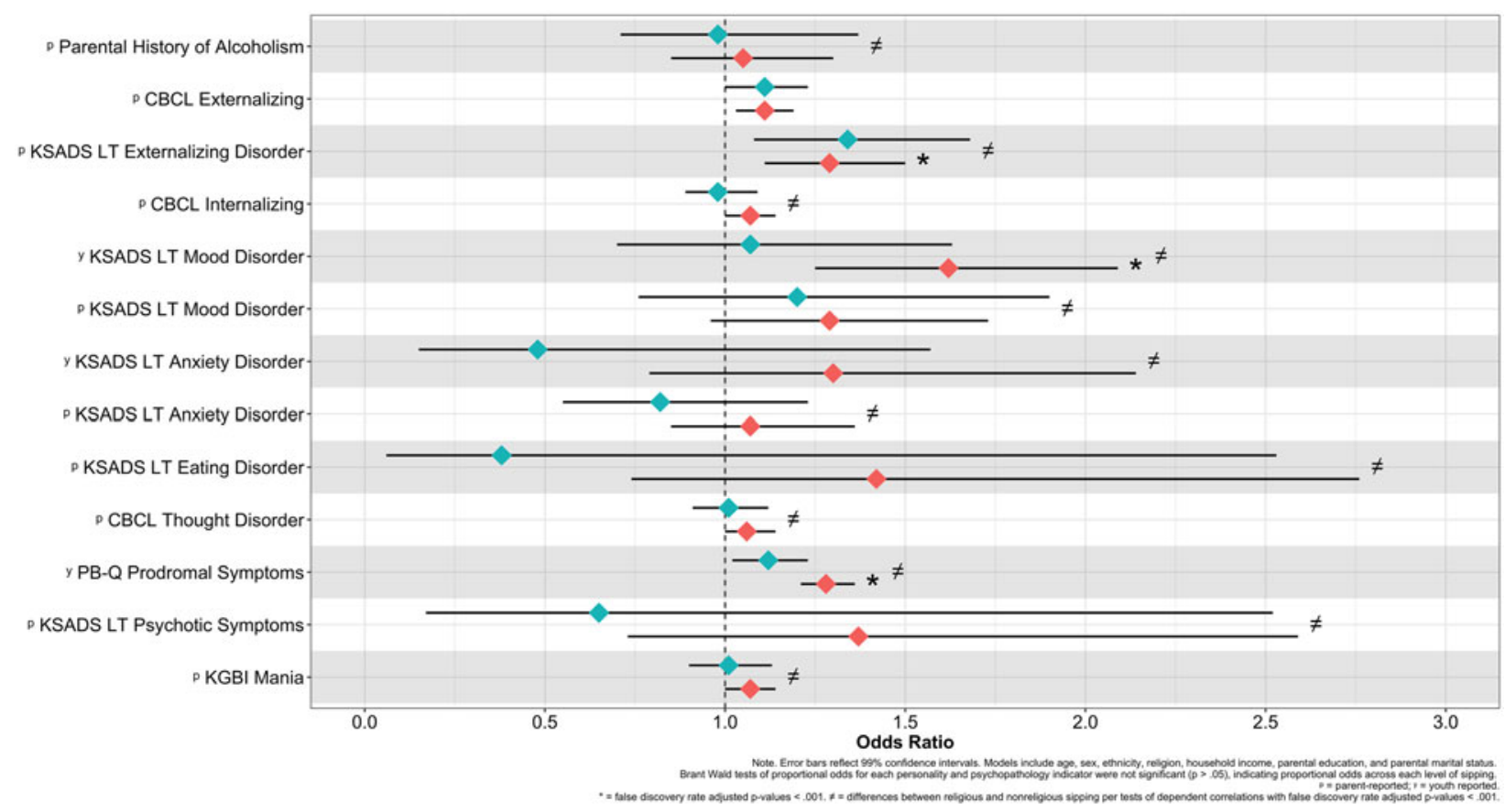

Figure 2. Odds of sipping as a function of youth- and parent-reported psychopathology.

and symptoms of psychosis were unassociated with sipping, and hence the effects we describe were exclusive to youth-reported experiences. We encourage future research exploring and adjudicating each of these hypotheses.

Inconsistent with the existing literature, we did not find that features of impulsivity or externalizing were associated with earlier alcohol initiation, nor did we find that parental history of alcohol problems was associated with sipping (Acheson, Richard, Mathias, \& Dougherty, 2011). Given that these findings are relatively well replicated (e.g., Dawe et al., 2007), we find the lack of support for these effects surprising. At the same time, we suspect that the former finding was due to restriction of range in the age of first sip indicator given that few children have reported sipping alcohol at all by ages 9 or 10. One potential explanation for the essentially null association between family history of alcohol problems and alcohol sipping is that there are competing tendencies at play in this association. Family history of alcohol problems is associated with both imitative and aversive transmission (Harburg, Davis, \& Caplan, 1982); most offspring of moderate drinkers drink moderately (imitative transmission), whereas some children of heavy drinks abstain from drinking (aversive transmission). In this way, parental alcohol problems may be a risk factor for early alcohol initiation for some children, and protective against it for others. We look forward to follow-up examinations of these questions as the $\mathrm{ABCD}$ cohort ages, and as youth begin experimenting with alcohol and other substances.

Finally, also inconsistent with our hypotheses, we also found that youth-reported traits reflecting lack of premeditation, positive urgency, and sensation seeking were associated with increased religious sipping; these effects were equivalent in magnitude as those for nonreligious sipping. These findings suggest that sipping in even a religious context is associated with elevated aspects of impulsivity. They also broadly corroborate those of Colder and colleagues (2018), who recently reported that youth who reported sipping with parental permission also reported higher levels of surgency and externalizing behavior compared with those who did not. There are a number of interpretations of these findings, which cannot necessarily be reconciled at present.

First, it is possible that impulsive youth show more interest in alcohol, and therefore ask parents to try it or seek out other religiously sanctioned opportunities to drink. As such, parents may allow sipping in the home to reduce curiosity about alcohol (Jackson et al., 2012; see also Colder et al., 2018). Relatedly, less impulsive children may be less likely to avail themselves to the novel experience of sipping alcohol and be more cautious in their approach to this adult-like behavior. Second, the classifying of a sipping occasion as "religious" or "nonreligious" could be related to personality dispositions. Specifically, there may be some attributional bias towards a social sanctioned "excuse" among those more prone to externalizing. As such, it is possible that there is some unmeasured (or at least unmodeled) third variable that induces a spurious association between select impulsivity-related measures and religious sipping. Third, impulsive or novelty-seeking parents may be more inclined to allow their children to sip in the home. Each of these possible explanations for the unexpected associations between certain impulsigenic traits and religious sipping are interesting but are not addressable with the current data.

\section{Strengths, limitations, and future directions}

Several notable strengths of the current study include a deeper assessment of sipping and its context than is typical of the literature (cf., Jackson, Barnett et al., 2015), which is generally limited to assessing whether or not children have sipped alcohol; distinguishing between religious and nonreligious sipping; targeting sipping early on in the lifespan (Donovan \& Molina, 2008, 2014); and including a wide range of presumed relevant individual difference characteristics (personality, psychopathology) that are known risk factors for alcohol use and misuse among 
adolescents and adults (see Jackson, Colby et al., 2015, for review). Additionally, we used a large sample of youth, which allowed for better powered tests of relatively small individual differences in sipping, given the relatively low base rate of sipping at this age. Lastly, all data were collected in a structured testing environment (Donovan \& Molina, 2014) as opposed to by means of a schoolbased survey (Jackson, Barnett et al., 2015). As such, our testing conditions may have been more conducive to honest reporting given that we probed sensitive and illicit behaviors.

A number of limitations are associated with our study. First, a limiting factor of targeting sipping in relatively young children resulted in relatively low frequencies of sipping overall, and even lower frequencies for indicators like finishing a complete drink. We expect that sipping will become more variable with age. Given the longitudinal nature of the ABCD study design, it will be important to track sipping among these same participants across development, targeting the extent to which individual differences variables are prospectively associated with sipping, and are associated with onset, chronicity, and increased frequency of sipping across time (Jackson, Barnett et al., 2015). Second, we assessed a number of DSM-5 psychiatric conditions that have relatively low base rates in the population, and in children in particular (e.g., mood disorder). This low variability in diagnostic indicators of psychopathology contributed to large standard errors around their associations with sipping, and as such some unreliability in their estimated effect sizes.

Third, we focused exclusively on early alcohol consumption, which was a practical decision given that rates of other substance use in the baseline ABCD sample were too low to yield adequately powered examinations of their correlates. For instance, at baseline, $.68 \%$ of participants reported nicotine use, $.10 \%$ reported cannabis use, and all other forms of substance use were reported by less than .05\% of the sample (Lisdahl et al., in preparation); also, bear in mind that these figures do not indicate regular use and instead could indicate experimenting with the substance even a single time. Although not examined here, it is entirely possible that alcohol sipping shares personality and psychopathology correlates with other forms of early substance use or experimentation. In fact, we suspect that many, if not most, correlates of alcohol sipping are substance use general (King, Iacono, \& McGue, 2004). We look forward to examinations of this possibility as rates of substance use increase in subsequent waves of the ABCD data.

Fourth, although consistent with effect sizes reported in the literature (e.g., Gunn \& Smith, 2010; Jackson, Colby et al., 2015), our observed effects were small in magnitude, explaining no more than $3 \%$ of the variance in sipping altogether. The existing literature points to several other factors important in the development of sipping, which can be organized into at least five sets of factors: (a) dispositional and psychopathological characteristics like the ones we explored, (b) demographic characteristics, which include being male, White, and participating in a religion where alcohol consumption is at least somewhat religiously sanctioned (Lisdahl et al., in preparation); (c) physical context, including within-home alcohol availability and allied parenting practices that provide exposure to alcohol (e.g., asking the child to fetch or open an alcoholic beverage; Jackson et al., 2013; Jackson, Colby et al., 2015; Tael-Öeren, Naughton, \& Sutton, 2019) or encourage consumption of alcohol (Wadolowski et al., 2015); (d) other "proximal" factors, such as drinking motives and alcohol expectancies; and (e) other social or contextual factors, including perceived sibling and peer (Trucco, Colder, \& Wieczorek, 2011) approval of drinking, general peer delinquency, and general parental monitoring, warmth, control, support, and conflict (Donovan \& Molina, 2008; Jackson, Colby et al., 2015).

Taking stock of effect sizes reported in the literature and in the current study, it appears that the strongest factors implicated in sipping pertain to alcohol availability within the home and allied parenting practices that appear to sanction alcohol exposure and/ or consumption. These factors are generally associated with odds ratios exceeding 2 or 3 . Other contextual factors, such as sibling and peer approval of drinking, peer drinking, alcohol expectancies, and parenting behaviors, tend to yield comparable effects sizes as psychopathology and personality, with odds ratios rarely exceeding 2.

Together with the sipping literature to date, these findings paint a complex picture of precocious alcohol use and its nomological network, but they make one point especially clear: incipient alcohol use appears influenced by a broad array of factors, some dispositional and others contextual. Although psychopathology and personality is certainly only one part of the puzzle, we focused the current examination on psychopathology- and personality-related factors given that they have been largely neglected in the sipping literature to date, in spite of well-replicated evidence that externalizing liability broadly construed is an important risk factor for early forms of alcohol use (Tully \& Iacono, 2016) and deviant behavior more generally. We hope that this investigation highlights the need to extend the nomological network of sipping well past established contextual (or environmental) indicators, and to psychopathological and dispositional ones.

Even so, we especially encourage future investigations that assess both contextual and dispositional factors that contribute to sipping. Such investigations are better equipped to examine the extent to which these sets of constructs combine either in an additive or interactive manner to predict precocious alcohol use even more strongly than either set of constructs in isolation. They are also better equipped to examine the extent to which putatively environmental factors, such as peer influence, are incrementally associated with sipping above and beyond individual difference characteristics, including impulsigenic traits, and vice versa. Each of these possibilities remain high priority for future research.

Fifth, most of the statistically significant effects between sipping and external criteria were for those that were youth- as opposed to parent-reported. Given that sipping was youth-reported, it is possible that method covariance contributed to these effects. At the same time, parents may not have knowledge of their child's illicit behavior, rendering youth-reported sipping more reliable than parent reports (Koning, Harakeh, Engels, \& Vollebergh, 2010). Further, youth-reported psychopathology and personality were not invariably associated with sipping, suggesting that children were able to differentiate among aspects of their personality and behavior. Nevertheless, this issue highlights the utility and challenges of multi-informant assessment of psychopathology (Martel, Markon, \& Smith, 2017).

Sixth, although our findings suggest that the correlates of sipping are similar to those of alcohol consumption later in adolescence (e.g., novelty seeking, impulsivity), our cross-sectional investigation is ill-equipped to address two important questions. The first is whether sipping bears robust developmental continuity with more extreme forms of alcohol consumption later in adolescence. The second is whether sipping is inherently pathological given its correlates. Jackson, Barnett et al., (2015) established that children who had sipped alcohol by grade 6 were at substantially increased risk to have consumed a full drink of alcohol, get drunk, 
engage in heavy episodic drinking, or use other substances by grade 9 . These findings suggest that there is certainly a connection between sipping and later, more extreme forms of drinking, but the two are by no means isomorphic (Wadolowski et al., 2015). Additionally, for many, alcohol use in adolescence is a relatively normative behavior (Spear, 2002), and is part of normative secular increases in risk-taking across adolescence that are thought to decrease by emerging adulthood (Caspi, Roberts, Shiner, 2005). This raises the issue of for whom sipping either increases risk for later drinking, or for whom sipping reflects risk for psychological maladjustment. Follow-up assessments of the ABCD cohort will not only be able to characterize the developmental consequences of this behavior but also identify those for whom such behavior is likely to prove problematic.

Here, the distinction we draw between religious and nonreligious sipping may be a critical consideration. Although we distinguish between religious and nonreligious forms of alcohol sipping (see also Morean et al., 2012), they are conflated with other types of sipping examined in the literature, such as with and without parental permission (e.g., Colder et al., 2018). We suspect that religious sipping is likely at least somewhat overlapping with sipping with parental permission, whereas nonreligious sipping is somewhat overlapping with sipping without parental permission. The ABCD data substantiate the latter claim but cannot bear on then former. In the ABCD baseline sample, children who reported nonreligious sipping were asked to indicate whether the sip was offered to them, or whether the sip was taken without permission. Ninety-three percent of children who reported sipping in a nonreligious context reported that the sip was taken without parental permission, whereas $.3 \%$ reported that they sipped because it was offered to them (the other 7 or so percent reported that they "accidentally" took a sip).

This indicates, then, that studies examining the correlates of sipping without parental permission and nonreligious sipping are probing highly similar constructs. Religious sipping is probably most likely to occur with parental permission, and within highly structured and supervised settings. Based on most of the observed correlates of religious sipping, it is possible that this form of early alcohol use is not necessarily pathological or indicative of later problematic alcohol use. Our nonreligious sipping indicator, in contrast, may reflect risk for later forms of alcohol use. Some research corroborates this speculation, finding that early alcohol initiation outside but not inside family gatherings, such as with peers, was uniquely associated with increased risk for later alcohol problems (Warner \& White, 2003). Still, based on its observed correlates, it may be premature to conclude that nonreligious sipping reflects an inherently pathological behavior, and instead may simply reflect a tendency to try new things. We look forward to longitudinal extensions of the work we present here, which will bear on the extent to which sipping presages later forms of alcohol use and other behaviors of clinical concern.

\section{Conclusion}

There is now considerable evidence that impulsivity is a broad risk factor for precocious alcohol use (e.g., Stautz \& Cooper, 2013). We extended this literature by demonstrating that sipping, which is potentially an early form of alcohol consumption (Donovan \& Molina, 2008, 2014; Jackson, Barnett et al., 2015; see also Maggs et al., 2019), is associated with other psychological and dispositional factors, namely psychopathology and traits associated with increased mood dysregulation or novelty seeking, in addition to impulsivity. Others have argued that sipping is not an early form of problematic alcohol use given that it tends not to be associated with known correlates of adolescent alcohol use when alcohol use is operationalized as having more than at least half of a drink (Wadolowski et al., 2015).

Our findings are not necessarily compatible with this argument, and instead hint towards developmental continuity between early forms of alcohol use and later excess alcohol consumption and related problems, both of which appear encouraged in part by impulsigenic traits and other potentially transdiagnostic aspects of psychopathology (i.e., emotion dysregulation, novelty seeking). Ultimately, our findings have the potential to contribute to earlier identification of youth at risk for substance use disorders. We encourage future research tracing the longitudinal unfolding of sipping and its relations with psychopathology and personality, including factors that moderate the trajectory of alcohol use across development. We also encourage further research that considers the public health implications of sipping, such as the extent to which early alcohol sipping among youth, regardless of context, is pathological and should be discouraged.

Supplementary material. The supplementary material for this article can be found at https://doi.org/10.1017/S0954579420000541

Financial support. Data used in the preparation of this article were obtained from the Adolescent Brain Cognitive Development (ABCD) Study (https:// abcdstudy.org), held in the NIMH Data Archive (NDA). This is a multisite, longitudinal study designed to recruit more than 10,000 children age 9-10 and follow them over 10 years into early adulthood. The ABCD Study is supported by the National Institutes of Health and additional federal partners under award numbers U01DA041022, U01DA041028, U01DA041048, U01DA041089, U01DA041106, U01DA041117, U01DA041120, U01DA041134, U01DA041148, U01DA041156, U01DA041174, U24DA041123, U24DA041147, U01DA041093, and U01DA041025. A full list of supporters is available at https://abcdstudy.org/federal-partners.html. A listing of participating sites and a complete listing of the study investigators can be found at https://abcdstudy.org/Consortium_Members.pdf. $\mathrm{ABCD}$ consortium investigators designed and implemented the study and/or provided data but did not necessarily participate in analysis or writing of this report. This manuscript reflects the views of the authors and may not reflect the opinions or views of the $\mathrm{NIH}$ or $\mathrm{ABCD}$ consortium investigators. The $A B C D$ data repository grows and changes over time. The $A B C D$ data used in this report came from DOI 10.15154/1503209.

\section{References}

Achenbach, T. M., \& Rescorla, L. A. (2001). Manual for the ASEBA school-age forms and profiles. Burlington: University of Vermont.

Acheson, A., Richard, D. M., Mathias, C. W., \& Dougherty, D. M. (2011). Adults with a family history of alcohol related problems are more impulsive on measures of response initiation and response inhibition. Drug and Alcohol Dependence, 117, 198-203. doi:10.1016/j.drugalcdep.2011.02.001

Babor, T. F., Hofmann, M., DelBoca, F. K., Hesselbrock, V., Meyer, R. E., Dolinsky, Z. S., \& Rounsaville, B. (1992). Types of alcoholics, I: Evidence for an empirically derived typology based on indicators of vulnerability and severity. Archives of General Psychiatry, 49, 599-608. doi:10.1001/ archpsyc.1992.01820080007002

Barch, D. M., Albaugh, M. D., Avenevoli, S., Chang, L., Clark, D. B., Glantz, M. D., ... \& Alia-Klein, N. (2018). Demographic, physical and mental health assessments in the adolescent brain and cognitive development study: Rationale and description. Developmental Cognitive Neuroscience, 32, 55-66.

Bjork, J. M., Hommer, D. W., Grant, S. J., \& Danube, C. (2004). Impulsivity in abstinent alcohol-dependent patients: relation to control subjects and type 1-/type 2-like traits. Alcohol, 34, 133-150. doi:10.1016/j.alcohol.2004.06.012

Caspi, A., Roberts, B. W., \& Shiner, R. L. (2005). Personality development: Stability and change. Annual Review of Psychology, 56, 453-484. doi:10.1146/annurev.psych.55.090902.141913 
Cloninger, C. R. (1987). Neurogenetic adaptive mechanisms in alcoholism. Science, 236, 410-416. doi:10.1126/science.2882604

Colder, C. R., Shyhalla, K., \& Frndak, S. E. (2018). Early alcohol use with parental permission: Psychosocial characteristics and drinking in late adolescence. Addictive Behaviors, 76, 82-87. doi:10.1016/j.addbeh.2017. 07.030

Cyders, M. A., Smith, G. T., Spillane, N. S., Fischer, S., Annus, A. M., \& Peterson, C. (2007). Integration of impulsivity and positive mood to predict risky behavior: development and validation of a measure of positive urgency. Psychological Assessment, 19, 107-118. doi:10.1037/1040-3590.19.1.107

Dawe, S., Loxton, N. J., Gullo, M. J., Staiger, P. K., Kambouropoulos, N., Perdon, L., \& Wood, A. (2007). The role of impulsive personality traits in the initiation, development, and treatment of substance misuse problems. In Translation of addictions science into practice (pp. 321-339). San Diego: Elsevier.

Dawson, D. A. (2000). The link between family history and early onset alcoholism: Earlier initiation of drinking or more rapid development of dependence?. Journal of Studies on Alcohol, 61(5), 637-646.

DeWit, D. J., Adlaf, E. M., Offord, D. R., \& Ogborne, A. C. (2000). Age at first alcohol use: a risk factor for the development of alcohol disorders. American Journal of Psychiatry, 157, 745-750. doi:10.1176/appi.ajp.157.5.745

Dom, G., Hulstijn, W., \& Sabbe, B. G. C. C. (2006). Differences in impulsivity and sensation seeking between early-and late-onset alcoholics. Addictive Behaviors, 31, 298-308. doi:10.1016/j.addbeh.2005.05.009

Donovan, J. E. (2009). Estimated blood alcohol concentrations for child and adolescent drinking and their implications for screening instruments. Pediatrics, 123, e975-e981. doi:10.1542/peds.2008-0027

Donovan, J. E., \& Molina, B. S. (2008). Children's introduction to alcohol use: sips and tastes. Alcoholism: Clinical and Experimental Research, 32, 108119. doi:10.1111/j.1530-0277.2007.00565.x

Donovan, J. E., \& Molina, B. S. (2011). Childhood risk factors for early-onset drinking. Journal of Studies on Alcohol and Drugs, 72, 741-751. doi:10.15288/jsad.2011.72.741

Donovan, J. E., \& Molina, B. S. (2014). Antecedent predictors of children's initiation of sipping/tasting alcohol. Alcoholism: Clinical and Experimental Research, 38, 2488-2495. doi:10.1111/acer.12517

Dvorak, R. D., Sargent, E. M., Kilwein, T. M., Stevenson, B. L., Kuvaas, N. J., \& Williams, T. J. (2014). Alcohol use and alcohol-related consequences: Associations with emotion regulation difficulties. The American Journal of Drug and Alcohol Abuse, 40, 125-13. doi:10.3109/00952990.2013.877920

Ellickson, P. L., Tucker, J. S., \& Klein, D. J. (2003). Ten-year prospective study of public health problems associated with early drinking. Pediatrics, 111, 949-955. doi:10.1542/peds.111.5.949

Ellickson, S. L., Tucker, J. S., Klein, D. J., \& McGuigan, K. A. (2001). Prospective risk factors for alcohol misuse in late adolescence. Journal of Studies on Alcohol, 62, 773-782. doi:10.15288/jsa.2001.62.773

Febrero-Bande, M., \& de la Fuente, M. O. (2012). Statistical computing in functional data analysis: The $\mathrm{R}$ Package fda.usc. Journal of Statistical Software, 51, 1-28. doi:10.18637/jss.v051.i04

Garavan, H., Bartsch, H., Conway, K., Decastro, A., Goldstein, R. Z., Heeringa, S., ... Zahs, D. (2018). Recruiting the ABCD sample: design considerations and procedures. Developmental Cognitive Neuroscience, 32, 16-22. doi:10.1016/j.dcn.2018.04.004

Grant, B. F., Stinson, F. S., \& Harford, T. C. (2001). Age at onset of alcohol use and DSM-IV alcohol abuse and dependence: a 12-year follow-up. Journal of Substance Abuse, 13, 493-504. doi:10.1016/S0899-3289(01)00096-7

Gray, J. A. (1982). The neuropsychology of anxiety. New York: Oxford University Press.

Gunn, R. L., \& Smith, G. T. (2010). Risk factors for elementary school drinking: Pubertal status, personality, and alcohol expectancies concurrently predict fifth grade alcohol consumption. Psychology of Addictive Behaviors, 24, 617-627. doi:10.1037/a0020334

Haeny, A. M., Gueorguieva, R., Morean, M. E., Krishnan-Sarin, S., DeMartini, K. S., Pearlson, G. D., ... O'Malley, S. S. (2019). The Association of Impulsivity and Family History of Alcohol Use Disorder on Alcohol Use and Consequences. Alcoholism: Clinical and Experimental Research.

Harburg, E., Davis, D. R., \& Caplan, R. (1982). Parent and offspring alcohol use: Imitative and aversive transmission. Journal of Studies on Alcohol, 43 (5), 497-516.
Hundt, N. E., Kimbrel, N. A., Mitchell, J. T., \& Nelson-Gray, R. O. (2008). High BAS, but not low BIS, predicts externalizing symptoms in adults. Personality and Individual Differences, 44, 565-575. doi:10.1016/ j.paid.2007.09.018

Hussong, A. M., Jones, D. J., Stein, G. L., Baucom, D. H., \& Boeding, S. (2011). An internalizing pathway to alcohol use and disorder. Psychology of Addictive Behaviors, 25, 390-404. doi:10.1037/a0024519

Jackson, K. M., Barnett, N. P., Colby, S. M., \& Rogers, M. L. (2015). The prospective association between sipping alcohol by the sixth grade and later substance use. Journal of Studies on Alcohol and Drugs, 76(2), 212-221.

Jackson, K. M., Colby, S. M., Barnett, N. P., \& Abar, C. C. (2015). Prevalence and correlates of sipping alcohol in a prospective middle school sample. Psychology of Addictive Behaviors, 29, 766-778. doi:10.1037/adb0000072

Jackson, C., Ennett, S. T., Dickinson, D. M., \& Bowling, J. M. (2012). Letting children sip: Understanding why parents allow alcohol use by elementary school-aged children. Archives of Pediatrics \& Adolescent Medicine, 166, 1053-1057. doi:10.1001/archpediatrics.2012.1198

Jackson, C., Ennett, S. T., Dickinson, D. M., \& Bowling, J. M. (2013). Attributes that differentiate children who sip alcohol from abstinent peers. Journal of Youth and Adolescence, 42, 1687-1695. doi:10.1007/s10964-012-9870-8

Jernigan, T. L., \& Brown, S. A., \& ABCD consortium coordinators. (2018). Introduction. Developmental Cognitive Neuroscience, 32, 1-3. doi:10.1016/ j.den.2018.02.002

Johnson, S. L., Carver, C. S., \& Joormann, J. (2013). Impulsive responses to emotion as a transdiagnostic vulnerability to internalizing and externalizing symptoms. Journal of Affective Disorders, 150(3), 872-878.

Kapur, S. (2003). Psychosis as a state of aberrant salience: a framework linking biology, phenomenology, and pharmacology in schizophrenia. American Journal of Psychiatry, 160, 13-23. doi:10.1176/appi.ajp.160.1.13

Karcher, N. R., Barch, D. M., Avenevoli, S., Savill, M., Huber, R. S., Simon, T. J., ... \& Loewy, R. L. (2018). Assessment of the Prodromal questionnaire-brief child version for measurement of self-reported psychoticlike experiences in childhood. JAMA Psychiatry, 75(8), 853-861.

King, K. M., \& Chassin, L. (2007). A prospective study of the effects of age of initiation of alcohol and drug use on young adult substance dependence. Journal of Studies on Alcohol and Drugs, 68, 256-265. doi:10.15288/jsad.2007.68.256

King, S. M., Iacono, W. G., \& McGue, M. (2004). Childhood externalizing and internalizing psychopathology in the prediction of early substance use. Addiction, 99, 1548-1559. doi:10.1111/j.1360-0443.2004.00893.x

Kobak, K. A., Kratochvil, C. J., Stanger, C., \& Kaufman, J. (2013). Computerized screening of comorbidity in adolescents with substance or psychiatric disorders. Anxiety Disorders and Depression. (La Jolla, CA).

Koning, I. M., Harakeh, Z., Engels, R. C., \& Vollebergh, W. A. (2010). A comparison of self-reported alcohol use measures by early adolescents: Questionnaires versus diary. Journal of Substance Use, 15, 166-173. doi:10.3109/14659890903013091

Lenth, R., Singmann, H., Love, J., Buerkner, P., \& Herve, M. (2018). Emmeans: Estimated marginal means, aka least-squares means. 2018. R package version 1.4. Retrieved from https://cran.r-project.org/web/packages/emmeans/ index.html.

Lisdahl, K. M., Sher, K. J., Conway, K. P., Gonzalez, R., Ewing, S. W. F., Nixon, S. J., ... Heitzeg, M. (2018). Adolescent brain cognitive development (ABCD) study: Overview of substance use assessment methods. Developmental Cognitive Neuroscience, 32, 80-96. doi:10.1016/j.dcn.2018.02.007

Lisdahl, K. M., Tapert, S., Sher, K. J., Gonzalez, R., Nixon, S. J., Ewing, S. W. F., \& Conway, K. P., \& \{ABCD Consortium Investigators\} \& Heitzeg, M. (in preparation). Substance use patterns in 9-10 year olds: Baseline findings from the Adolescent Brain Cognitive Development (ABCD) Study.

Loewy, R. L., Pearson, R., Vinogradov, S., Bearden, C. E., \& Cannon, T. D. (2011). Psychosis risk screening with the Prodromal Questionnaire-brief version (PQ-B). Schizophrenia Research, 129, 42-46. doi:10.1016/ j.schres.2011.03.029

Maggs, J. L., Staff, J., Patrick, M. E., \& Wray-Lake, L. (2019). Very early drinking: Event history models predicting alcohol use initiation from age 4 to 11 years. Addictive Behaviors, 89, 121-127. doi:10.1016/j.addbeh.2018.09.030

Martel, M. M., Markon, K., \& Smith, G. T. (2017). Research review: Multi-informant integration in child and adolescent psychopathology 
diagnosis. Journal of Child Psychology and Psychiatry, 58, 116-128. doi:10.1111/jcpp.12611

Marwaha, S., Broome, M. R., Bebbington, P. E., Kuipers, E., \& Freeman, D. (2013). Mood instability and psychosis: Analyses of British national survey data. Schizophrenia Bulletin, 40, 269-277. doi:10.1093/schbul/sbt149

McGue, M., Iacono, W. G., Legrand, L., Malone, S., \& Elkins, I. (2001). The origins of age at first drink: Associations with substance-use disorders, disinhibitory behavior and psychopathology, and P3 amplitude. Alcoholism: Clinical and Experimental Research, 25, 1156-1165. doi:10.1111/ j.1530-0277.2001.tb02330.x

Morean, M. E., Corbin, W. R., \& Fromme, K. (2012). Age of first use and delay to first intoxication in relation to trajectories of heavy drinking and alcoholrelated problems during emerging adulthood. Alcoholism: Clinical and Experimental Research, 36, 1991-1999. doi:10.1111/j.1530-0277.2012.01812.x

Muthén, L. K., \& Muthén, B. O. (1998-2017). Mplus user's guide (8th ed.). Los Angeles, CA: Muthén \& Muthén.

Pagliaccio, D., Luking, K. R., Anokhin, A. P., Gotlib, I. H., Hayden, E. P., Olino, T. M., ... Barch, D. M. (2016). Revising the BIS/BAS Scale to study development: Measurement invariance and normative effects of age and sex from childhood through adulthood. Psychological Assessment, 28, 429-442. doi:10.1037/pas0000186

R Core Team. (2018). R: A language and environment for statistical computing. Vienna, Austria: R Foundation for Statistical Computing. https://www.Rproject.org/.

Rice, J. P., Reich, T., Bucholz, K. K., Neuman, R. J., Fishman, R., Rochberg, N., ... Begleiter, H. (1995). Comparison of direct interview and family history diagnoses of alcohol dependence. Alcoholism: Clinical and Experimental Research, 19, 1018-1023. doi:10.1111/j.1530-0277.1995.tb00983.x

Rubio, G., Jiménez, M., Rodríguez-Jiménez, R., Martínez, I., Ávila, C., Ferre, F., ... Palomo, T. (2008). The role of behavioral impulsivity in the development of alcohol dependence: A 4-year follow-up study. Alcoholism: Clinical and Experimental Research, 32, 1681-1687. doi:10.1111/j.1530-0277.2008. 00746.x

Segarra, P., Poy, R., López, R., \& Moltó, J. (2014). Characterizing Carver and White's BIS/BAS subscales using the five factor model of personality. Personality and Individual Differences, 61, 18-23. doi:10.1016/j.paid.2013. 12.027

Sher, K. J., Grekin, E. R., \& Williams, N. A. (2005). The development of alcohol use disorders. Annual Review in Clinical Psychology, 1, 493-523. doi:10.1146/annurev.clinpsy.1.102803.144107

Sher, K. J., Littlefield, A., \& Lee, M. (2018). Personality processes related to the development and resolution of alcohol use disorders. In H. E. Fitzgerald \& L. I. Puttler (Eds.), Alcohol use disorders: A developmental science approach to etiology (pp. 285-304). New York, NY: Oxford University Press.

Sher, K. J., Trull, T. J., Barthoolow, B. D., \& Vieth, A. (1999). Personality and alcoholism: Issues, methods, and etiological processes. In K. E. Leonard \& H. T. Blane (Eds.), Psychological theories of drinking and alcoholism (2nd ed.) (pp. 54-105). New York, NY: Guilford Press.

Spear, L. P. (2002). The adolescent brain and the college drinker: Biological basis of propensity to use and misuse alcohol. Journal of Studies on Alcohol (Suppl. 14), 71-81.

Stautz, K., \& Cooper, A. (2013). Impulsivity-related personality traits and adolescent alcohol use: A meta-analytic review. Clinical Psychology Review, 33, 574-592. doi:10.1016/j.cpr.2013.03.003
Steiger, J. H. (1980). Tests for comparing elements of a correlation matrix. Psychological Bulletin, 87, 245-251. doi:10.1037/0033-2909.87.2.245

Stueve, A., \& O'Donnell, L. N. (2005). Early alcohol initiation and subsequent sexual and alcohol risk behaviors among urban youths. American Journal of Public Health, 95, 887-893. doi:10.2105/AJPH.2003.026567

Tael-Öeren, M., Naughton, F., \& Sutton, S. (2019). The relationship between parental attitudes and children's alcohol use: A systematic review and metaanalysis. Addiction, 114, 1527-1546. doi:10.1111/add.14615

Townsend, L., Kobak, K., Kearney, C., Milham, M., Andreotti, C., Escalera, J., ... \& Rice, D. (2020). Development of three web-based computerized versions of the Kiddie Schedule for Affective Disorders and Schizophrenia child psychiatric diagnostic interview: Preliminary validity data. Journal of the American Academy of Child \& Adolescent Psychiatry, 59(2), 309-325.

Trucco, E. M., Colder, C. R., \& Wieczorek, W. F. (2011). Vulnerability to peer influence: A moderated mediation study of early adolescent alcohol use initiation. Addictive Behaviors, 36, 729-736. doi:10.1016/j.addbeh.2011.02.008

Trull, T. J., \& Sher, K. J. (1994). Relationship between the five-factor model of personality and Axis I disorders in a nonclinical sample. Journal of Abnormal Psychology, 103, 350-360. doi:10.1037/0021-843X.103.2.350

Tully, E. C., \& Iacono, W. G. (2016). An integrative common liabilities model for the comorbidity of substance use disorders with externalizing and internalizing disorders. In K. J. Sher (Ed.), The Oxford handbook of substance use and substance use disorders: Volume 2 (pp. 187-214). New York: Oxford University Press.

Verdejo-García, A., Lawrence, A. J., \& Clark, L. (2008). Impulsivity as a vulnerability marker for substance-use disorders: Review of findings from highrisk research, problem gamblers and genetic association studies. Neuroscience \& Biobehavioral Reviews, 32(4), 777-810.

Warner, L. A., \& White, H. R. (2003). Longitudinal effects of age at onset and first drinking situations on problem drinking. Substance Use \& Misuse, 38 (14), 1983-2016.

Wadolowski, M., Hutchinson, D., Bruno, R., Aiken, A., Clare, P., Slade, T., ... Mattick, R. P. (2015). Early adolescent alcohol use: are sipping and drinking distinct? Alcoholism: Clinical and Experimental Research, 39, 1805-1813. doi:10.1111/acer.12826

Watts, A. L., Smith, G. T., Barch, D. M., \& Sher, K. J. (2020). Factor structure, measurement and structural invariance, and external validity of an abbreviated youth version of the UPPS-P Impulsive Behavior Scale. Psychological Assessment, 32, 336-347.

Wood, S. N. \& Scheipl, F. (2017). gamm4: Generalized additive mixed models using $\mathrm{mgcv}$ and lme4. R package version 0.2 . Retrieved from http://cran.rproject.org/package $=$ gamm 4 .

Young, S. E., Corley, R. P., Stallings, M. C., Rhee, S. H., Crowley, T. J., \& Hewitt, J. K. (2002). Substance use, abuse and dependence in adolescence: Prevalence, symptom profiles and correlates. Drug and Alcohol Dependence, $68,309-322$.

Youngstrom, E. A., Findling, R. L., Danielson, C. K., \& Calabrese, J. R. (2001). Discriminative validity of parent report of hypomanic and depressive symptoms on the General Behavior Inventory. Psychological Assessment, 13, $267-$ 276. doi:10.1037/1040-3590.13.2.267

Youngstrom, E. A., Frazier, T. W., Demeter, C., Calabrese, J. R., \& Findling, R. L. (2008). Developing a ten item mania scale from the parent general behavior inventory for children and adolescents. The Journal of Clinical Psychiatry, 69, 831-839. doi:10.4088/JCP.v69n0517 